\title{
'Feeling hot, hot, hot': is there a role for exercise in the management of vasomotor and other menopausal symptoms?
}

\author{
Amanda J Daley, Helen Stokes-Lampard, Christine MacArthur
}

\section{Background}

Until recently, hormone replacement therapy (HRT) was a popular treatment for vasomotor symptoms (hot flushes and night sweats) but evidence ${ }^{1,2}$ reporting adverse effects of hormone therapy and negative media reports have raised important questions about its use. It seems that both clinicians' and patients' confidence in the use of HRT has been undermined, as demonstrated by the large reduction in HRT prescriptions in recent years. ${ }^{3}$

As large numbers of women are choosing to avoid HRT, it is increasingly important to identify evidence-based lifestyle interventions that have the potential to reduce prevalence and severity of vasomotor symptoms. One option might be exercise, particularly given that evidence involving other populations ${ }^{4}$ has reported regular participation to have positive effects upon some of the other kinds of symptoms and health concerns that many menopausal women experience and for which they might also seek treatment (i.e. cognition, depression, fatigue, bone health, weight maintenance and cardiovascular diseases). The Royal College of Obstetricians and Gynaecologists (RCOG) advises that regular aerobic exercise may help with menopausal symptoms ${ }^{5}$ and studies report that women believe exercise to be useful for symptom mangement. 6

\section{What evidence do we have?}

Observational research involving large samples of women has been supportive of a positive relationship between exercise participation and vasomotor symptoms ${ }^{7-9}$ but we must also be mindful that several smaller observational studies have found no association or mixed findings. ${ }^{10,11}$ One of our own studies $^{12}$ did not find a significant difference in vasomotor symptom scores between active women and sedentary women, although positive associations with other menopausal symptoms such as depressed mood and somatic symptoms were found. On balance, the observational evidence is supportive that participation in regular exercise can reduce the frequency and severity of vasomotor symptoms in menopausal women but of course conclusive information can only be reliably provided by randomised controlled trials (RCTs). To date, trial evidence has been mixed. Aiello et al.13 randomised postmenopausal women to an exercise

J Fam Plann Reprod Health Care 2007; 33(3): 143-145

Department of Primary Care and General Practice, Medical School, University of Birmingham, Birmingham, UK Amanda J Daley, C Psychol, PhD, Lecturer in Health Psychology Helen Stokes-Lampard, MBBS, MRCGP, Clinical Research Fellow and General Practitioner

Department of Public Health and Epidemiology, Medical School, University of Birmingham, Birmingham, UK Christine MacArthur, PhD, Professor of Maternal and Child Epidemiology

Correspondence to: Dr Amanda Daley, Department of Primary Care and General Practice, Clinical Sciences Building, University of Birmingham, Edgbaston, Birmingham B15 2TT, UK.

E-mail: a.daley@bham.ac.uk intervention or a stretching/relaxation group for 12 months. Analyses showed no significant differences in the odds of having hot flushes or night sweats at follow-up between the groups, but only $54 \%$ of the sample was symptomatic at baseline, limiting its contribution to this debate. In a nonrandomised trial ${ }^{14}$ symptomatic women assigned to an exercise intervention plus education about climacteric symptoms did not report fewer vasomotor symptoms than those having usual care, although the general menopause measure used showed significantly lower symptoms for the exercise group at follow-up. Another small RCT ${ }^{15}$ (on which the RCOG based their advice about the benefits of exercise for symptom management) compared the effects of exercise with HRT on menopause-related outcomes in symptomatic women. The authors concluded that both interventions were effective in reducing general menopausal symptomatology, but the number of hot flushes decreased significantly at follow-up only in the HRT group. A further trial ${ }^{16}$ compared a 12-month exercise intervention with a control group and also found reduced prevalence of general menopausal symptomatology, favouring the exercise group. While the sample sizes in these trials reporting positive effects have been small, they have provided an indication of the potential that exercise might have as a treatment for menopausal symptoms, although evidence regarding vasomotor symptoms specifically is not clear.

\section{Proposed mechanisms of action}

It is hypothesised that endorphin concentrations in the hypothalamus decrease as estrogen production declines, enhancing release of norepinephrine (noradrenaline) and serotonin. Exercise may exert a similar effect to HRT in the amelioration of vasomotor symptoms by increasing the presence of hypothalamic and peripheral $\beta$-endorphin production. In addition, there is evidence that as endorphins increase, the frequency and amplitude of luteinising hormone decreases, ${ }^{17,18}$ which regulates gonadotropin-releasing hormone levels. Furthermore, research has shown that active individuals have higher basal levels of $\beta$-endorphins than those who are inactive; on these grounds exercise may help to stabilise the thermoregulatory centre and diminish the risk of hot flushes. But a counter argument is that a large amount of adipose tissue (typically seen in inactive/sedentary women) leads to the conversion of adrenal androgens to estrogens, which may in turn alleviate symptoms. Thus, exercise may actually increase the severity and incidence of vasomotor symptoms by reducing adipose tissue. These contradictory explanations clearly highlight the need for future research. It has been suggested ${ }^{19}$ that exercise can improve mental health outcomes by providing a distraction or 'time out' strategy from daily worries and that exercise can enhance individuals' feelings of accomplishment, thereby enhancing self-esteem.

Promoting exercise in menopausal women Evidence on the effects of exercise on menopausal symptoms, specifically vasomotor symptoms, from large RCTs of symptomatic women is still lacking. We do know, 
however, that exercise can provide menopausal-aged women with many other physical health benefits at a time in their lives when they might need them the most (i.e. cardiovascular and bone health). In addition, some menopausal women who seek medical help will present with a combination of vasomotor and psychological symptoms and the National Institute for Health and Clinical Excellence (NICE) ${ }^{20}$ now advocate that mild-tomoderately depressed patients should be advised about the benefits of exercise.

Given that the process of exercise typically causes individuals to produce acute responses such as heat and perspiration, it seems reasonable to expect that menopausal women might in fact perceive exercise as a rather counter intuitive treatment that would exacerbate their hot flushes rather than prevent or reduce them. Thus, it is easy to see how 'rest is best' might seem the more attractive option during the menopause transition, particularly if night sweats are causing disturbed sleep and subsequent fatigue. However, contrary to popular opinion, people often report feeling more alive and refreshed after exercise than before. ${ }^{21}$ We should also consider evidence that suggests the effects of exercise upon symptom relief may be mediated by exercise intensity since it has been suggested that the production of $\beta$-endorphins is more likely to occur during high-intensity rather than low-intensity exercise. ${ }^{22}$ In reality, this might be problematic since menopausal women are more likely to enjoy, and respond to the suggestion from clinicians to exercise as part of treatment, if the recommendation is for participation in low- to moderate-intensity exercise. If it is the case that vigorous exercise is required, the ability and motivation of many menopausal women to regularly participate is likely to be low and this might also reduce the likelihood that general practitioners (GPs) and gynaecologists would want to promote exercise participation for symptom management.

The success of exercise as a potential treatment for menopausal symptoms inevitably relies on clinicians being equipped with the correct information about exercise. However, studies have shown that many GPs are not knowledgeable about the current recommendations for physical activity to achieve health benefits ${ }^{23}$ and we have no reason to assume that this would be any different for gynaecologists. As a reminder, current recommendations for physical activity to achieve health benefits ${ }^{4}$ are that adults should achieve at least 30 minutes a day of at least moderate intensity physical activity on five or more days of the week. If that seems difficult to achieve, for many people 45-60 minutes of moderate intensity physical activity a day is likely to be necessary for weight management. There is a concession, however, in that this exercise target does not have to be achieved in a single session; it can be accumulated in 10-minute bouts throughout the day.

\section{Conclusions}

Large observational studies of symptomatic women have shown an association between exercise and fewer vasomotor and other menopause-related symptoms. Small trials have reported improvements in menopausal symptomatology but evidence regarding vasomotor symptoms specifically is not clear. There are, however, plausible biological mechanisms by which exercise might have an effect on vasomotor symptoms. While the RCOG has advised that regular aerobic exercise may help relieve menopausal symptoms, the most common of which is hot flushes, large trials are clearly required before menopausal symptomatic women can be advised that we know this to be the case. This is particularly relevant today, given that
HRT may not provide menopausal women with all the protective health benefits that previously it was thought to provide, and because large numbers of women are now choosing not to take HRT. In the meantime, despite the potential difficulties of getting middle-aged, symptomatic women to exercise regularly, as there are no apparent longterm adverse effects of exercise in this population and good evidence that exercise can benefit other menopause-related symptoms as well as cardiovascular and bone health, we would encourage GPs and gynaecologists to include exercise in the 'therapeutic toolbox' and consider its use in appropriate patients.

Statements on funding and competing interests

Funding Helen Stokes-Lampard is funded by a Department of Health Researcher Development Award.

Competing interests None identifed.

\section{References}

1 Writing Group for the Women's Health Initiative Investigators. Risk and benefits of estrogen plus progestin in healthy postmenopausal women; principal results from the Women's Health Initiative randomised controlled trial. JAMA 2002; 288: 321-333.

2 Million Women Study Collaborators. Breast cancer and hormone replacement therapy in the Million Women Study. Lancet 2003; 362: 419-427.

3 Lawton B, Rose S, McLeod D, Dowell A. Change in use of hormone replacement therapy after the report from the Women's Health Initiative: cross sectional survey of users. BMJ 2003; 327: 845-846.

4 Department of Health. At Least Five a Week: Evidence on the Impact of Physical Activity and its Relationship to Health. A Report from the Chief Medical Officer. 2004. http://www.dh.gov.uk/en/Publicationsandstatistics/Publications/ PublicationsPolicyAndGuidance/DH_4080994 [Accessed 14 January 2007].

5 Royal College of Obstetricians and Gynaecologists. Alternatives to HRT for Management of Symptoms of the Menopause (Scientific Advisory Committee Opinion Paper 6). May 2006. http://www.rcog.org.uk/index.asp?pageid $=1561$ [Accessed 23 January 2007].

6 Daley AJ, MacArthur C, McManus R, Stokes-Lampard H, Wilson S, Roalfe A, et al. Factors associated with the use of complementary medicine and non-pharmacological interventions in symptomatic menopausal women. Climacteric 2006; 9: 336-346.

7 Progetto Menopausa Italia Study Group. Factors associated with climacteric symptoms in women around menopause attending menopause clinics in Italy. Maturitas 2005; 52: 181-189.

8 Gold EB, Sternfeld B, Kelsey JL, Brown C, Mouton C, Reame $\mathrm{N}$, et al. Relation of demographic and lifestyle factors to symptoms in a multi-racial/ethnic population of women 40-55 years of age. Am J Epidemiol 2002; 152: 463-473.

9 Li C, Samsioe G, Borgfeldt C, Lidfeldt J, Agardh CD, Nerbrand C. Menopause-related symptoms: what are the background factors? A prospective population-based cohort study of Swedish women (The Women's Health in Lund Area study). Am J Obstet Gynecol 2003; 189: 1646-1653.

10 Wilbur J, Dan A, Hedricks C, Holm K. The relationship among menopausal status, menopausal symptoms, and physical activity in midlife women. Fam Community Health 1990; 13: 67-78.

11 Avis NE, Crawford SL, McKinley SM. Psychosocial, behavioral and health factors related to menopause symptomatology. Womens Health 1997; 3: 103-120.

12 Daley A, Macarthur C, Stokes-Lampard H, McManus R, Wilson $\mathrm{S}$, Mutrie N. Exercise participation, body mass index and health-related quality of life in women of menopausal age. $\mathrm{Br} J$ Gen Pract 2007; 57: 130-135.

13 Aiello EJ, Yasui Y, Tworoger SS, Ulrich CM, Irwin ML, Bowen $\mathrm{D}$, et al. Effect of a yearlong moderate-intensity exercise intervention on the occurrence and severity of menopausal symptoms in post-menopausal women. Menopause 2004; 11: 382-388.

14 Ueda MA. 12-week structured education and exercise program improved climacteric symptoms in middle-aged women. J Physiol Anthropol Appl Hum Sci 2004; 23: 143-148.

15 Lindh-Åstrand L, Nedstrand E, Wyon Y, Hammar M. Vasomotor symptoms and quality of life in previously sedentary postmenopausal women randomised to activity or estrogen 
therapy. Maturitas 2003; 48: 97-105.

16 Villaverde-Gutierrez C, Araujo E, Cruz F, Roa JM, Barbosa W, Ruiz-Villaverde G. Quality of life of rural menopausal women in response to a customized exercise programme. J Adv Nurs 2006; 54: 11-19.

17 Kalra SP, Simpkins JW. Evidence for noradrenergic mediation of opioid effects on luteinizing hormone secretion. Endocrinology 1981; 109: 776-782.

18 Reid RL, Hoff JD, Yen SSC, Li CH. Effects of exogenous beta h-endorphin on pituitary hormone secretion and its disappearance rate in normal human subjects. J Clin Endocrin Metabol 1981; 52: 1179-1183.

19 Daley AJ. Exercise therapy and mental health in clinical populations: is exercise therapy a worthwhile intervention? Adv Psychiatr Treat 2002; 8: 262-270.
20 National Institute for Health and Clinical Excellence. Depression: Management of Depression in Primary and Secondary Care (NICE Clinical Guidance No. 23). 2004 http://guidance.nice.org.uk/CG23 [Accessed 14 January 2007].

21 Eriksen W, Bruusgaard D. Do physical leisure time activities prevent fatigue? A 15-month prospective study of nurses' aides. Br J Sports Med 2004; 38: 331-356.

22 Daniel M, Martin AD, Carter J. Opiate receptor blockade by naltrexone and mood state after acute physical activity. $\mathrm{Br} \mathrm{J}$ Sports Med 1992; 26: 111-115.

23 Douglas F, Torrance N, van Teijlingen E, Meloni S, Kerr A Primary care staff's views and experiences related to routinely advising patients about physical activity. A questionnaire survey. BMC Public Health 2006; 6:138 doi:10.1186/1471. 2458-6-138.
Effectiveness of levonorgestrel emergency contraception given before or after ovulation a pilot study. Novikova N, Weisberg, E, Stanczyk FZ, Croxatto HB, Fraser IS Contraception 2007; 75: 112-118

Research on emergency contraception (EC) is bedevilled by ethical objections to conducting placebo-controlled trials, problems of indirect estimates of efficacy and the difficulty that EC pill trials include only single exposure to unprotected sex whereas in real life this is often not the case. We are urged to offer the option of a copper intrauterine device (IUD, which is known to have extremely high efficacy - considerably greater than levonorgestrel (LNG) EC - but which may not be immediately available, nor be as acceptable to clients as a pill. Although there is still some uncertainty about the efficacy of LNG $\mathrm{EC}$, studies show it is definitely much better than doing nothing and this applies when even women present between 72 and 120 hours after the event.

Research on mode of action has shown the only convincing mechanism to be delaying or arresting follicular development and blocking or delaying/blunting the luteinising hormone (LH) surge; clearly this will not work if ovulation has already happened. Effects at the endometrial level that might prevent implantation have been shown in some studies for the Yuzpe regimen (PC4) but not for LNG.

Analysis of Yuzpe regimen studies has shown that EC is more effective when given earlier in the follicular phase. Until recently there were no data on effectiveness of LNG EC according to day of the cycle

This small Australian pilot study seeks to remedy this situation. Ninety-nine women had their serum progesterone, estradiol and $\mathrm{LH}$ measured at the time of pill ingestion. EC was given at up to 120 hours after unprotected sex. Women were followed up 4-6 weeks later by telephone and any pregnancies were confirmed by ultrasound. Endocrine data showed that 41 were in the follicular phase, 30 were periovulatory and 28 were in the luteal phase. Fifty-one women had had sex in a 5-day window prior to ovulation. There were three pregnancies, all of which occurred in the 17 women who had had sex in the peri-ovulatory period and were treated after ovulation; three or four pregnancies would have been expected. No pregnancies occurred in the 34 women who took EC before or around the time of ovulation; four or five pregnancies would have been expected.

The study also reports, as have other studies, major discrepancies between women's self-report of stage of the cycle and the dating calculation based on endocrine parameters. This reinforces the principle that EC should virtually never be withheld because of low risk calculated from the history.

If these results can be confirmed in adequately powered studies, then this will be further evidence that LNG EC does not work by preventing implantation (i.e. it does not have the capacity to intervene after fertilisation). This would call into question the use of LNG EC in the second half of the cycle. Greater pressure would be put on services to be able to offer women an emergency IUD if they are in the following groups:

- Cycle dates uncertain

- 48 hours after unprotected sex

- Thought to be in second half of the cycle at the time of unprotected sex

- Multiple exposure.

Reviewed by Sam Rowlands, MD, FRCGP Senior Lecturer, Warwick Medical School, Warwick, UK

Therapeutic options in the polycystic ovary syndrome. Bhathena RK. J Obstet Gynaecol 2007; 27: 123-129

The polycystic ovary syndrome (PCOS) is the most common endocrine disorder affecting women. Many of the patients we encounter in everyday women's health care practice will therefore have manifestations of this condition and will need objective and up-to-date advice. The topics discussed in Mr Bhathena's recent review include the recently agreed definition of PCOS, its clinical features and the therapeutic options available for the management of its presenting problems such as hirsutism and other androgenic effects, menstrual disturbance, obesity and anovulatory infertility.

Mr Bhathena draws attention to the fact that women with PCOS, particularly those who are obese, need long-term advice and support in order to reduce the risks of hypertension, lipid disorders, impaired glucose tolerance anc cardiovascular disease in later life, all of which are associated with the fundamental problem of insulin resistance that is probably the main causative factor of the syndrome. The author deals with various approaches to achieving weight reduction, including the potential for the use of metformin, but I was disappointed that there was no assessment of the current fashion of advising low glycaemic index (low GI) diets, fo which evidence of efficacy and safety has yet to be confirmed.

The review is helpful in mentioning some of the benefits of hormonal contraception for women with PCOS. Those with hirsutism or acne will be helped by oestrogenic low-dose combined oral contraceptives (COC) containing desogestre (Marvelon ${ }^{\circledR}$ or Mercilon $^{\circledR}$ ) or drosperinone $\left(\right.$ Yasmin $\left.^{\circledR}\right)$, although initial treatment with a contraceptive dermatological preparation containing cyproterone acetate (Dianette ${ }^{\circledR}$, Clairette ${ }^{\circledR}$ ) is conventional. Women with menstrual disturbance will be helped either by a COC or by the levonorgestrel IUS (Mirena ${ }^{\circledR}$ ), which may also be of value in reducing the longterm risk of endometrial carcinoma due to the unopposed action of oestradiol.

This concise yet comprehensive review provides a very helpful introduction to the many issues involved in the management of this common but complex condition.

Reviewed by David H Horwell, FRCOG, MFFP Consultant Gynaecologist and Obstetrician, Luton \& Dunstable Hospital NHS Foundation Trust, Luton, UK

Does methotrexate confer a significant advantage over misoprostol alone for early medical abortion? A retrospective analysis of 8678 abortions. Aldrich T, Winikoff B. $B r J$ Obstet Gynaecol 2007; 114: 555-562

This was a retrospective review of 8678 cases of women who had medical abortion ( $<8$ weeks) with either a regimen of (a) misoprostol alone or (b) a combination of methotrexate and misoprostol (different routes of administration). Initial treatment doses were given in the clinics, but subsequent misoprostol (self-administered) and abortion occurred at home. Patients attended the clinics 2 weeks later. The study was conducted in a Latin American country where abortion is highly restrictive/illegal so the clinics were anonymised (for security reasons). The aim was to compare the efficacy of the combined methotrexate and misoprostol only regimens. Abortion rates were significantly better with the combined regimens than misoprostol alone $(83 \%$ vs $77 \%$, respectively). It is possible that this reflects the two modes of action: misoprostol on uterine activity and the antimitotic effect of methotrexate upon conceptus. The authors concluded that the use of methotrexate was important in maximising success in countries where abortion is highly restrictive and mifepristone is unavailable. Methotrexate has adverse effects on bowel, liver and hair (loss). In contrast, mifepristone is well tolerated, allows reduced doses of misoprostol (fewer side effects) with a complete abortion rate of $97 \%$. Unfortunately, women in these countries needlessly suffer greater morbidity and complications because they continue to be denied this safer more effective treatment.

Reviewed by Sharon Cameron, MD, MRCOG Consultant Gynaecologist, Dean Terrace Centre, Edinburgh, UK 